\title{
Reading Glossed Passages in English to Improve Comprehension: An Eye Tracking Study
}

\author{
Izzammuddin Isnin $^{a}$ \\ a172278@siswa.ukm.edu.my \\ Centre for Research in Language and Linguistics, \\ Faculty of Social Sciences and Humanities \\ Universiti Kebangsaan Malaysia, Malaysia \\ Nurjanah Mohd Jaafar ${ }^{b}$ \\ nurjanah@ukm.edu.my \\ Centre for Research in Language and Linguistics, \\ Faculty of Social Sciences and Humanities \\ Universiti Kebangsaan Malaysia, Malaysia
}

\begin{abstract}
Glosses or short explanations of vocabulary items are commonly found in language learning materials. Research that use offline learning measures to examine effects of glosses on learning found that they are useful in facilitating vocabulary acquisition and overall text comprehension. This paper reports a small-scale study that combined an offline measure of learning with online measures of reading behaviour in an attempt to provide a more comprehensive picture of reading and learning with glossed passages. The eye tracking methodology was used to provide insights into the cognitive processing of reading. A group of 15 university undergraduates read four glossed and non-glossed passages in English and answered comprehension questions afterwards. The findings revealed that glossed and non-glossed passages were read differently with readers attempting to integrate glosses and text information in the former. Vocabulary knowledge was found to predict comprehension performance and to some extent, the processing of glosses. The findings also suggest that moderate amount of attention could be more useful for comprehension as too much attention appeared to indicate comprehension difficulties. Suggestions to promote more strategic and useful processing of glossed passages are discussed.
\end{abstract}

Keywords: glosses; reading; processing; eye tracking; English as a second language

\section{INTRODUCTION}

The inclusion of glosses or annotations in texts is a common strategy to help facilitate the acquisition of new or difficult vocabulary items and aid overall text comprehension. Glosses provide readers with brief explanations, paraphrases, or translations of key vocabulary items in the text. Hence, instead of interrupting reading by flipping the pages of a dictionary or typing away on a keyboard when googling the meaning of a word, readers can get a quicker explanation when glosses are integrated in the text.

Glosses are now available in a variety of forms. The most common are textual and pictorial, and it is now rather customary to come across audio and even dynamic, pictorial glosses. By allowing readers to look up the meaning of words, readers are provided with more opportunity to interact and engage with the text (Plass \& Jones, 2005). Various studies have found that glosses do facilitate the learning of a second language (L2) and its various competencies such as vocabulary acquisition and reading comprehension (Plass et al., 2003;

${ }^{a}$ Main author

${ }^{b}$ Corresponding author 
Plass \& Jones, 2005). However, as pointed out by Warren et al. (2018), many of these studies used offline measures of learning such as post-reading comprehension or vocabulary recall and retention tasks to study the effects of glosses.

The use of online measures of reading behaviour to examine cognitive processes during reading of glosses is relatively new. One advantage of using online measures of reading behaviour is that they provide moment-to-moment indication of the cognitive processes underlying the complex cognitive tasks of reading and comprehension (Rayner, 2009). Using the eye tracking methodology allows researchers to, for instance, determine whether the glosses are read or attended to by readers, or whether they are simply ignored. It also allows the researchers to determine how long or how frequent the reading of glosses is. When such online measure is combined with offline learning measures, researchers could make informed decisions about reading behaviour and how it implicates or relates to learning. Additionally, all these information can inform the design of language learning materials, even informing whether or not glossary is necessary in the first place. After all, if readers were able to comprehend a text along with new or difficult vocabulary items without sparing any attention to the glossary section, why would material designers even bother to include glosses?

The present study used the eye tracking methodology to explore how a group of 15 university undergraduates at a tertiary institution process glossed passages in English and how the processing could be influential on overall text comprehension. The role of English vocabulary knowledge in comprehending the passages was also examined. Three research questions were formulated to achieve this aim:

1. How do ESL readers process English passages with and without glosses?

2. What is the relationship between English vocabulary knowledge and comprehension outcome?

3. What is the relationship between processing of glosses and comprehension outcome?

\section{LITERATURE REVIEW}

\section{VOCABULARY AND READING COMPREHENSION}

Vocabulary is crucial in various aspects of language such as reading comprehension, communicating, and understanding of the language as a whole (de Groot \& van Hell, 2005; Koda, 2004). With regard to reading comprehension, vocabulary knowledge compared to other factors such as prior knowledge and literacy in the native language, has consistently been shown to be a strong predictor (Grabe, 2009; Koda, 2004). In order to understand a reading material, one must know a certain amount of its vocabulary. According to Nation (2006), for unassisted comprehension in English, a vocabulary of 8000 word families provides $98 \%$ of the coverage to deal with written texts. In addition to vocabulary size (or quantity), a reader also needs to possess a variety of knowledge aspects regarding a word, such as its forms, meanings, collocations and grammatical functions (Nation, 2001; Schmitt, 2008; Sulaiman et al., 2018).

Koda (2004) speculates that the relationship between vocabulary knowledge and reading comprehension is more complex than the simple 'vocabulary-supports-comprehension' view. Vocabulary knowledge and reading comprehension may be mutually interdependent and have a two-way reciprocal relationship. It is indeed true that word knowledge is crucial to understanding texts, but it is also true that with a more global understanding of the text and the context in which the word appears, its more precise meaning can be determined.

In the present study, glosses were incorporated more as a means to support overall text comprehension. The ability to determine the meaning of new vocabulary items from a global understanding of text suggests the role of word familiarity and frequency of occurrence. The 
present study, however, mostly used pseudowords as glosses and they appeared only once or twice in the passages. A pseudoword is a string of letters that is phonologically and orthographically legal in a given language but is not in its lexicon (Chuang et al., 2021; Warren et al., 2018). An example of English pseudoword is "bamble" [bæm.bəl].

\section{THE ROLE OF GLOSSES IN FACILITATING LANGUAGE LEARNING}

The inclusion of glosses in a reading material provides readers with brief explanations, paraphrases or translations of key vocabulary items in the text. In printed materials, glosses are normally inserted at the bottom of the page or next to and in line with the main text. Glosses in these materials are normally textual and/or pictorial. In addition to the textual and pictorial forms, digital and online reading materials can incorporate glosses in audio, audio-visual, and video formats. With these materials, a reader can simply click on a glossed word to see its L1 translation (textual gloss), its corresponding picture (pictorial gloss) and/or listen to its pronunciation (audio gloss). Having such electronic glosses instead of using dictionaries (traditional or electronic ones) is more useful as definitions or translations are more contextspecific (Golonka et al., 2014).

Glosses were found to facilitate reading comprehension as well as incidental and intentional vocabulary learning (Golonka et al., 2014). This is especially true in the case of glosses that combine verbal (text) and visual (pictorial) representations (Khezrlou et al., 2017; Plass et al., 2003). Including glosses in a reading material encourages readers to interact more actively with the material as glosses allow readers to look up the meaning of words while reading (Golonka et al., 2014; Plass \& Jones, 2005). Khezrlou et al. (2017) in particular found that readers in three experimental groups demonstrated vocabulary gains in the study, even though one group did not receive explicit instruction to make use of the glosses. However, readers who received explicit instruction to read the glosses before and while reading emerged superior in terms of vocabulary acquisition and reading comprehension. While these studies found that glosses are useful for language learning, several found that they were not helpful and made no difference (Ariew \& Ercetin, 2004; Cheng \& Good, 2009). This disparity might be due to the decision to focus on outcome-oriented investigations in which post-reading tasks were used to measure the outcome of the reading process.

It is argued here that exploring online cognitive processing of glosses in addition to the use of offline outcome-based measures is necessary to make more informed decisions about glosses and the reasons that underly successful and unsuccessful learning from reading texts with glosses. The present study used the eye tracking methodology to examine the cognitive processes that occur when ESL readers encounter English passages with glosses. This methodology allows the researchers to determine whether the glosses are read or attended to by readers, or whether they are simply being ignored. As mentioned above, by using both process and outcome measures, the researchers could have a more comprehensive picture on how glosses contribute to overall comprehension. This methodology also allows the researchers to determine whether the processing of glossed passages can be contributed to the amount of English vocabulary that the readers possess.

\section{EYE TRACKING IN READING RESEARCH}

Reading research that employs the eye tracking methodology uses an eye tracker to record the position of a reader's eyes as they move across a visual stimulus, i.e., the reading material. A basic record of eye movements is made up of a sequence of fixations and saccades (Rayner, 2009). A fixation is the period of time in which the eyes remain still as they focus on and 
encode new information from a certain area of a visual stimulus. A saccade refers to the rapid movement of the eyes between two successive fixations.

Eye tracking is frequently used in reading research because the data provide momentto-moment indication of cognitive processes underlying the reading process (Rayner, 2009). This link between eye movements and cognitive processes is illustrated in Just and Carpenter's (1980) immediacy and eye-mind assumptions. These assumptions propose that during reading readers attempt to interpret content words as they are encountered and this interpretation takes place immediately, without delay. The eyes continue to fixate on a particular word for as long as it is being processed or "until they have processed it as far as they can" (p. 350). Fixations on a visual input hence are an indicator of what the mind is currently processing. The length of these fixations is an indicator of how long the cognitive processing takes place. Eye tracking measures or indices therefore provide spatial and temporal resolution of visual attention. Higher values in the length and number of fixations could suggest processing or comprehension difficulties (Rayner et al., 2006; Scheiter \& Eitel, 2017; Sulaiman et al., 2020).

Although the eyes do not encode new information during saccades, they are nevertheless useful indicators of cognitive processing. Frequent number of backward saccades or regressions for instance can also be an indicator of comprehension difficulty (Rayner, 2009). In multi-representational learning research, saccades or transitions that connect different representations (such as a paragraph and a diagram) are particularly useful as their frequency is taken to reflect the number of integrative attempts learners make when encountered with different representations (Mason et al., 2015; Scheiter \& Eitel, 2017). Higher number of transitions are associated with positive learning outcomes (Mason et al., 2013; Mason et al., 2015).

Research that utilises the eye tracking methodology to examine reading of glosses is relatively new. Three of them are briefly reviewed here. Warren et al. (2018) carried out an investigation on adult ESL learners to evaluate the effect of exposing L2 learners to different gloss types on vocabulary acquisition. The study found significant positive associations between post-test performance and the amount of attention on the target words (pseudonyms) and their glosses. Compared to the present study which used text-only glosses, Warren et al. (2018) used three types of glosses: text-only, text and picture, and picture only. More recently, Tham et al. (2019) conducted an eye tracking study that examined how Malaysian bilinguals processed English texts with cues (i.e., short translations of pseudowords). Rather than manipulating the type of glosses like Warren et al. (2018), Tham et al. (2019) manipulated the language of the cues and they found that the bilinguals processed both L1 and L2 cues in a similar manner when reading texts in their L2 (English). Their study however did not examine the link between processing of the cues and comprehension.

Sulaiman et al.'s (2020) study focused more on the overall reading of academic texts in English. Their participants were asked to read three articles, each of which includes four marginal glosses. After reading, the participants were asked to explain what they understood from the texts after reading. They were given one of these three labels based on their answers: able to recall and explain each text accurately, failed to recall all or some texts, or able to recall each text accurately. A snapshot of each participant's processing was included along with an example of scanpaths for each label. It was found that those who failed to recall the texts spent the longest time reading all three texts. Furthermore, many of them, regardless of the labels, found the texts difficult mostly because of the unfamiliar and difficult vocabulary. Sulaiman et al. (2020) suggested that the vocabulary used in academic texts could implicate text comprehension. Despite acknowledging that readers need adequate vocabulary knowledge to comprehend academic texts, the study did not measure the participants' vocabulary knowledge and establish its link with comprehension of the texts. The present study examined the 
relationship between these two variables to determine whether vocabulary knowledge is indeed instrumental in text comprehension.

\section{METHOD}

\section{PARTICIPANTS}

Fifteen undergraduates of a local public university participated in this study. Their age ranged from 22 to 25 (mean $=23$ years old) and all self-reported English as their L2. The sample comprised ESL undergraduates from different levels of English proficiency, determined from their performance in the Malaysian University English Test (MUET), a national English language proficiency test for university admissions. Overall, there were 3 low proficient participants (attained MUET Band 2, classified as limited users of English), 9 moderate proficient participants (attained MUET Bands 3 or 4, classified as modest or satisfactory users of English, respectively) and 3 high proficient participants (attained MUET Band 5, classified as proficient users of English). The participants were from different academic specialisations and all of them had normal or corrected-to-normal visions. All participants gave their consent to participate in the study.

\section{MATERIALS}

Four online passages in English were adapted and used as the stimuli: one without glosses (Passage A), and three with glosses (Passages B, C, and D). The passages were expository in nature. Passage A contained facts and origins of a minority ethnic group in Malaysia, Passage B contained unknown facts about dolphins, Passage $\mathrm{C}$ provided a description of a sunk ferry, and Passage D contained facts and origins of the opera. Table 1 summarises the characteristics of the passages in terms of their word counts and readability. The Flesch reading ease test is an assessment of the overall text's readability. It measures length, in that the ratings are based on the average number of syllables per word and words per sentence ("Get your document's readability and level statistics," 2018). Hence for a piece of writing, the longer its words and sentences are, the more difficult it is to read (Bailin \& Grafstein, 2001). On the whole, the values in Table 1 indicate that all four passages ranged from difficult to read to fairly difficult to read and age-appropriate for readers in upper secondary up to third year of tertiary education.

TABLE 1. Summary of text characteristics

\begin{tabular}{lcccc}
\hline Text characteristic & \multicolumn{4}{c}{ Passage } \\
\cline { 2 - 5 } & $\mathbf{A}$ & B $^{\mathbf{c}}$ & $\mathbf{C}$ & D \\
\hline Number of words & 186 & 184 & 194 & 132 \\
Flesch reading ease scored $^{\mathrm{d}}$ & 34.6 & 54 & 64.1 & 42.3 \\
\hline
\end{tabular}

Each glossed passage consisted of two components: the main text and the glossary. The glossary was placed after the main text, at the bottom of the passage. It contained three glosses. Next to each gloss were its part of speech placed in a parenthesis and its textual definition in English. Two out of the three glossed words in each passage were pseudowords. Pseudowords were used to control the effect of participants' previous exposure to the words and to ensure that learning is related to the processing of the glosses and their definitions rather than from prior experience (Horst, 2013). The one remaining glossed word in the glossary was an existing English word.

${ }^{c}$ For Passages $B-D$, word counts include words in both the main text and the glossary

${ }^{d}$ The scale goes from 0 (practically unreadable) to 100 (easy for any literate person) 
A reading comprehension task was administered after participants completed reading of each glossed passage. In total, there were three reading comprehension tasks (henceforth post-test). The post-test was a paper-and-pencil task, requiring the participants to write down their answers. Each post-test comprised three questions: two open-ended and one multiplechoice (i.e., four answer options with only one correct answer). Answers to each open-ended question were scored out of two according to their correctness and completeness, whereas a correct answer for the multiple-choice question received one mark. In sum, the maximum score for each post-test was five. Hence, the maximum score for all three post-tests was 15 .

To measure English vocabulary knowledge, the Lexical Test for Advanced Learners of English (LexTALE) was used (Lemhöfer \& Broersma, 2012). The test involves a yes/no visual lexical decision task and assesses the vocabulary knowledge of L2 English speakers. Its maximum score is 100. LexTALE was administered to the participants after the reading session has ended and was chosen to measure vocabulary knowledge for a number of reasons. Firstly, it correlated highly with other measures of English proficiency (e.g., the Quick Placement Test) and it was superior to other self-rating measures of English proficiency. Additionally, LexTALE only takes users around 3.5 minutes to complete and is fairly easy to administer as it can be administered online.

\section{APPARATUS AND EYE TRACKING MEASURES}

Eye tracking data were collected using a Tobii Pro TX300 eye tracker (Tobii Technology, Stockholm, Sweden) with a $300 \mathrm{~Hz}$ sampling rate. The eye tracker is not intrusive and does not require a head stabilisation system. The participants were therefore allowed to make minimal head movements. The stimuli were presented on a 23-inch TFT monitor with a resolution of 1920 x 1080 pixels. Data were recorded and analysed with Tobii Studio software.

\section{PROCEDURE}

Participants were called to the eye tracking laboratory individually. Upon arrival, they were first briefed about the study and its procedure. All participants were informed that they would be completing a background questionnaire and a reading stage. For the reading stage, the participants were asked to read all passages silently and carefully as they would have to answer some questions. They were informed that to navigate to the next screen, they had to click on the right mouse button and once they proceeded to a subsequent screen, they could not go back to the previous one as they could only move forward. There was no time limit and all participants read at their own pace.

The session commenced once the participants gave their informed consent. They started the session by completing the background questionnaire. Next, the reading stage commenced with a calibration test. After successful calibration, the participants read an instruction page on screen, followed by the four passages. After the presentation of each passage, a fixation cross was presented. The participants stopped to answer a post-test following completion of each glossed passage, i.e., Passages B, C and D. Figure 1 presents the presentation order of materials on screen. After answering the last post-test, participants completed the LexTALE online. The entire procedure took about 20 to 30 minutes. 


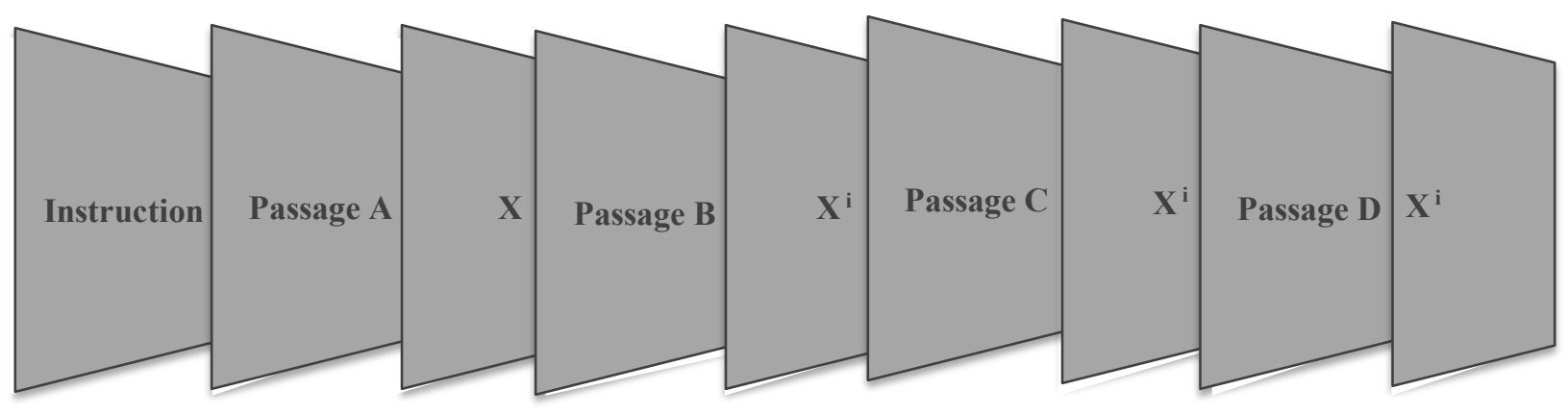

$X$ is a fixation cross.

$X^{i}$ Participants completed a pen-and-pencil comprehension task

FIGURE 1. Presentation order of stimuli

\section{DATA ANALYSIS}

To examine how the participants read the English passages with and without glosses, quantitative and qualitative data were analysed. For quantitative analysis, each glossed passage was segmented into two areas of interest (AOIs); one for the main text and another for the glossary. There was only one AOI for Passage A as it did not contain a glossary. The eye tracking metrices used to measure processing were total fixation duration (TFD) and total fixation count (TFC). TFD sums up the time for all fixations on a particular AOI whereas TFC sums up the number of fixations on a particular AOI. Both metrices were computed based on the AOIs. Besides the two eye tracking metrices, two other quantitative data were the LexTALE scores which measured the participants' English vocabulary knowledge, and the post-test scores which measured their comprehension of the passages.

The qualitative data used for this study were the participants' scanpaths. A scanpath is a visual representation "of eye-movement patterns that show a sequence of fixations and saccades in time and space" (Godfroid, 2019, p. 242). Scanpaths are typically represented by gaze plots which display information about individual fixations, their positions, and sequences (Godfroid, 2019; Mohd Yusof et al., 2020). A scanpath therefore can show a participant's gaze pattern when reading a visual stimulus.

\section{FINDINGS AND DISCUSSION}

In this section, the answers to the study's three research questions are presented and discussed in turn.

\section{THE PROCESSING OF ENGLISH PASSAGES WITH AND WITHOUT GLOSSES}

Both quantitative and qualitative analyses were carried out to answer this research question. The quantitative analysis was conducted on two eye tracking metrices, TFD and TFC on the two types of passages. For the non-glossed passage, as there was only one AOI, TFD was computed by summing up the duration for all fixations on the single AOI, whereas TFC was computed by summing up the frequency for all fixations on the AOI. TFD on each of the glossed passages was computed by summing up TFD on the two AOIs, i.e., the main text and the glossary. TFC on each of the glossed passages was computed by summing up TFC on both AOIs. Table 2 reports the means and standard deviations of the metrices by passage type. 
TABLE 2. Descriptive statistics of eye tracking metrices by type of passage

\begin{tabular}{cccccccc}
\hline \multicolumn{2}{c}{$\begin{array}{c}\text { Non-glossed passage } \\
\text { (Passage A) }\end{array}$} & \multicolumn{2}{c}{ Glossed Passage } \\
\cline { 2 - 8 } $\begin{array}{c}\text { TFD } \\
\text { (seconds) }\end{array}$ & TFC & $\begin{array}{c}\text { TFD } \\
\text { (seconds) }\end{array}$ & TFC & $\begin{array}{c}\text { TFD } \\
\text { (seconds) }\end{array}$ & TFC & TFD & TFC \\
Mean $(S D)$ & Mean $(S D)$ & Mean $(S D)$ & Mean $(S D)$ & Mean $(S D)$ & Mean $(S D)$ & Mean $(S D)$ & Mean $(S D)$ \\
\hline 54.46 & 236.13 & 57.33 & 246.20 & 66.21 & 284.67 & 53.60 & 229.60 \\
$(20.82)$ & $(78.23)$ & $(28.13)$ & $(103.20)$ & $(33.79)$ & $(126.83)$ & $(28.47)$ & $(99.52)$ \\
\hline
\end{tabular}

It appears that two out of the three glossed passages were read for a longer period (as indicated by TFD) and received more fixations (as indicated by TFC) compared to the passage without glosses. Passage D however was read for a shorter period and fixated less frequently compared to the non-glossed passage. This appears sensible considering that Passage D had the least word count (see Table 1). Since there were three glossed passages, it would be useful to look at the average TFD and TFC. Overall, TFD for the glossed passages was longer $(M=$ 59.72 seconds, $S D=26.67)$ and TFC $(M=253.49$ seconds, $S D=94.70)$. These values indicate that overall, the glossed passages were read for a longer period and received more fixations compared to the non-glossed passage. Higher values in fixation duration and fixation count could suggest comprehension difficulties during reading (Rayner et al., 2006; Scheiter \& Eitel, 2017; Sulaiman et al., 2020). The participants could have read the glossed passages longer because they contained more unfamiliar words compared to the non-glossed passage and they needed to map the unfamiliar words with their definitions in the glossary.

A qualitative examination of scanpaths provides an alternative view of how the participants process both types of passages. Instead of focusing on the amount of processing (as indicated by TFD and TFC), scanpaths are used below to describe the gaze patterns, i.e., the sequence of eye fixations and movements, as well as their direction (Warid et al., 2018).

Figure 2 shows an example of a participant's (coded as P06) scanpath when reading Passage A, the non-glossed passage. Fixations are represented by the neon green dots. The dots are numbered and the numbers represent the sequence of the fixations. The size of the dots are proportional with the duration of fixations. Smaller dots indicate shorter fixations. As seen in Figure 2, P06's fixations appear to begin on the first line from left to right, and downward to the diagonal left of the second line once reading of the first line was completed. This is the Zpath pattern, which is a typical gaze pattern for languages with alphabetic scripts which are read from left-to-right and top-to-bottom, like English (Cohn, 2013). Similar to Sulaiman et al.'s (2020) study, Passage A here was read word-by-word, line-by-line in a linear order. Also evident in Figure 2 are saccades, i.e., lines connecting two fixations, both forward and backward (or regressions). There are several saccades connecting the first and second paragraphs. These transitions are indicator that the reader is attempting to integrate information from the two paragraphs (Mason et al., 2015; Scheiter \& Eitel, 2017). 


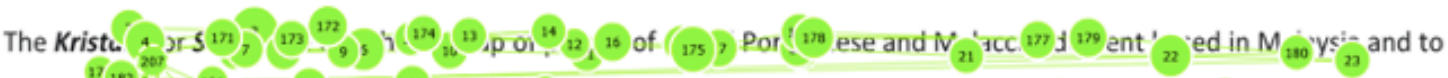

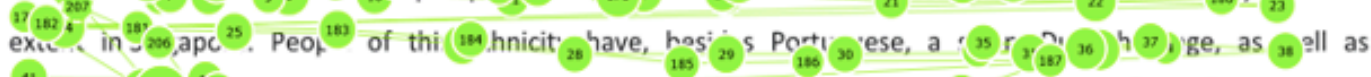

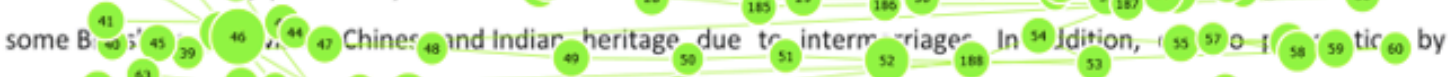

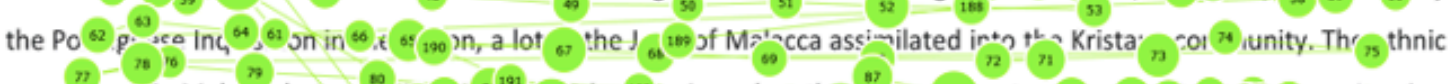

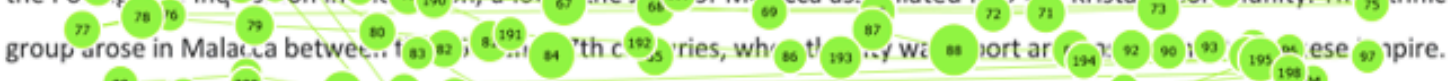

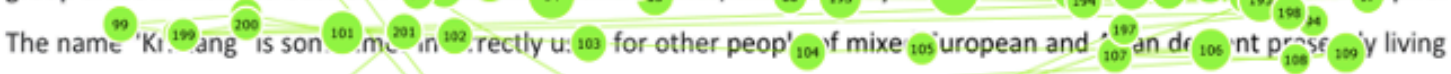
in Mal: 111 a and Singapore.

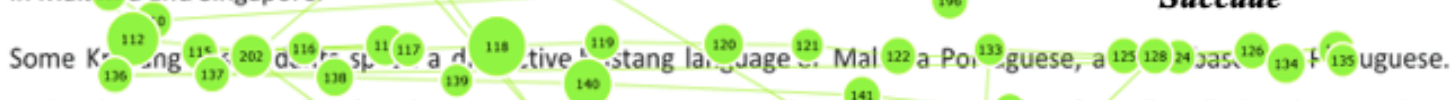

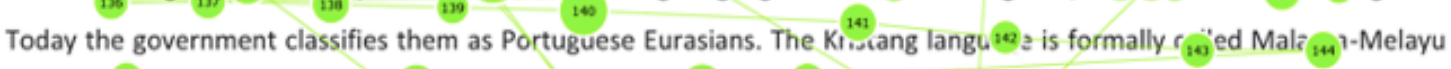

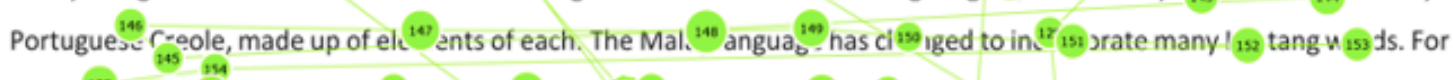

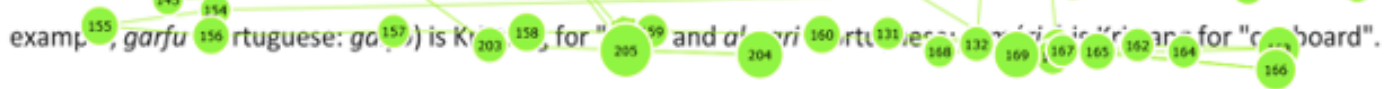

FIGURE 2. Typical example of a participant's scanpath when reading a non-glossed passage (Passage A) and an example of saccades connecting the two paragraphs

The scanpath seen in Figure 3 is an example of P06's scanpath when reading a glossed passage. The fixations on the main body shows a similar Z-path gaze pattern as Figure 2. P06 read from left to right, and downward. A number of overlapping fixations can also be seen indicating that some words were reread. We can also see some saccades or transitions connecting the main body and the glossary area indicating that the glosses were read and possibly being integrated with information in the main body. The scanpath in Figure 3 appeared more or less similar to the scanpath of a participant labelled as "able to recall and explain each text accurately" in Sulaiman et al. (2020, p. 67). Another participant in Sulaiman et al.'s (2020) study who also met these criteria was described to switch back and forth between the main text and the glosses.

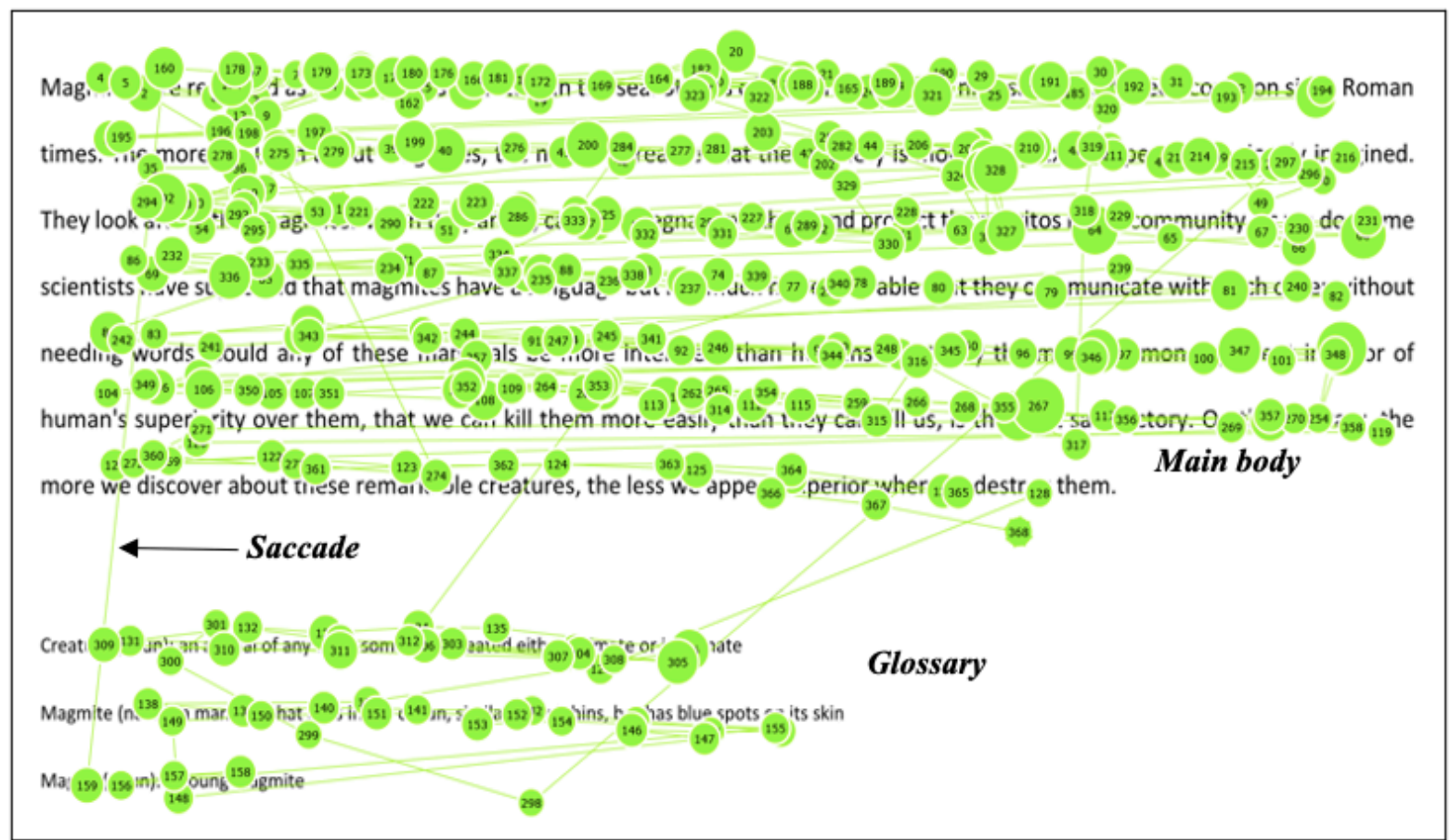

FIGURE 3. Typical example of a participant's scanpath when reading a glossed passage (Passage B) 


\section{THE RELATIONSHIP BETWEEN ENGLISH VOCABULARY KNOWLEDGE AND COMPREHENSION OUTCOME}

As reviewed earlier, vocabulary knowledge is considered as one of the strongest predictors of reading comprehension. If this was indeed the case, performance of the research participants in the post-test comprehension task could be explained by their English vocabulary knowledge. In theory, a positive relationship should emerge as the more vocabulary knowledge the participants have, the more able they are to comprehend the passages and do well in the posttest. As such, attention to the glosses and their definitions may not be the only variable explaining a successful text comprehension. Table 3 reports the means and standard deviations of the post-test scores by passage.

TABLE 3. Descriptive statistics of post-test scores by passage

\begin{tabular}{cccc}
\hline & Passage B & Passage C & Passage D \\
\hline $\begin{array}{c}\text { Scores } \\
\text { (scored out of 5) }\end{array}$ & Mean $(S D)$ & Mean $(S D)$ & Mean $(S D)$ \\
\cline { 2 - 4 } & $2.73(1.44)$ & $2.10(1.49)$ & $3.07(1.44)$ \\
\hline
\end{tabular}

To examine the relationship between English vocabulary knowledge and reading comprehension, a Pearson's correlation coefficient test was conducted on the participants' LexTALE scores $(M=72.37, S D=14.67)$ and the overall post-test scores $(M=7.90, S D=$ 3.31). The test shows a moderate positive relationship, $r=.572, p<.05$. This suggests that the participants' English vocabulary knowledge predicted their comprehension performance and the more English vocabulary knowledge they have, the more likely they were to perform better in the post-test. This finding corroborates past works which argue that readers need adequate vocabulary knowledge (e.g., vocabulary size, word forms and meanings) to comprehend a reading material successfully (Nation, 2001, 2006; Schmitt, 2008; Sulaiman et al., 2020).

\section{THE RELATIONSHIP BETWEEN PROCESSING OF GLOSSES AND COMPREHENSION OUTCOME}

We have already confirmed that English vocabulary knowledge is a predictor of comprehension of glossed passages. How about the processing of the glosses itself? Is it also a predictor of comprehension? In this case, TFD and TFC on the glossary AOIs of the three passages were examined and the average scores were computed. Pearson's correlation coefficient test was run on the TFD and TFC, as well as the overall post-test scores to examine the relationship between the processing of the glosses and reading comprehension. The test however did not reveal any significant associations between post-test scores and any of the eye tracking metrices, i.e., all $p \mathrm{~s}>.05$. For TFD and post-test, $r$ was -.27 , and for TFC and posttest, $r$ was -.08 . This lack of significance was not surprising given the small size of the sample, $N=15$.

To examine this issue further, the participants were grouped according to their post-test scores and each group's processing of the glosses was scrutinised. All 15 participants were therefore grouped into three; Group 1 consisted of those who scored 0 - 5, Group 2 members scored 6 - 10, whereas Group 3 members scored 11 - 15. Altogether, there were two members in Group 1, nine in Group 2, and four in Group 3. Descriptive statistics was used and reported in the following paragraphs to understand how reading comprehension could be related to the processing of glosses. Again, since there were three glossed passages, the average TFD and TFC on the glossary areas were computed. Table 4 presents the groups' means and standard deviations. 
TABLE 4. Descriptive statistics of eye tracking metrices on glosses by comprehension group

\begin{tabular}{cccc}
\hline $\begin{array}{c}\text { Comprehension } \\
\text { Group }\end{array}$ & $\begin{array}{c}\text { Comprehension } \\
\text { scores }\end{array}$ & $\begin{array}{c}\text { TFD on glossary } \\
\text { (seconds) }\end{array}$ & TFC on glossary \\
\cline { 2 - 4 } & $\operatorname{Mean}(\boldsymbol{S D})$ & Mean $(\boldsymbol{S D})$ & Mean $($ SD) \\
\hline 1 & $2.5(3.53)$ & $16.79(9.87)$ & $56.67(17.44)$ \\
2 & $7.44(1.67)$ & $9.07(6.85)$ & $38.96(27.69)$ \\
3 & $11.63(0.95)$ & $9.91(2.43)$ & $43.25(13.04)$ \\
\hline
\end{tabular}

Group 1 whose members scored the lowest in the post-test spent the most time and fixated most frequently on the glossary compared to the other two groups. Group 2, on the other hand, spent the shortest time and fixated least frequently on the glossary. Group 3's TFD and TFC on the glossary appeared to be somewhere in the middle between the other two.

From these results, it appears that spending too much or too little reading time on the glossary section may not necessarily be strategic nor useful for comprehension. The same is to be said about the number of fixations. Higher values on these metrices could actually be an indicator of comprehension difficulties. Indeed past studies have recorded systematic relationships between these metrices and comprehension difficulties (Rayner et al., 2006; Scheiter \& Eitel, 2017; Sulaiman et al., 2020). Group 1 members therefore could be having difficulties comprehending the glossary section. Their LexTALE scores support this proposition as Group 1 also had the lowest LexTALE scores $(M=63.38, S D=18.21)$.

The scanpath of one of the Group 1's members (coded as P07G1) in Figure 4 shows that although the participant read the glossary area, it was read in a similar manner as the main body. Once the reading of the last line of the main body was completed, fixations moved downwards, diagonally to the left of the glossary area. The glosses were read one after the other, line by line in a linear manner, without any interruptions or regressions back to the main body. Contrast this with Figure 3 where a typical scanpath when reading a glossed passage shows multiple saccades connecting the glosses and the main body. The scanpath in Figure 4 suggests that P07G1 might not have integrated information contained in the two areas. The participant's scanpaths for the remaining glossed passages also showed a similar pattern. This pattern is very much similar to those of three participants in Sulaiman et al.'s (2020). The three participants labelled as "failed to recall all or some of the texts" (p. 67) were described to read the main text first one by one, word by word before moving to the glosses on their right. These glosses were read line by line, from top to bottom.

The findings for this research question suggest that moderate attention on the glosses as demonstrated by Group 3 may be key to successful comprehension. Too much attention as discussed previously could actually indicate processing difficulties and as exemplified in Sulaiman et al.'s (2020) study, those who did not recall the texts had longer fixation duration than other participants. Too little attention on the other hand could indicate that the glosses are being neglected. However, despite this suggestion, it is acknowledged here that it would be difficult for any readers to determine whether they are paying too little, moderate or too much attention on any part of the text. 


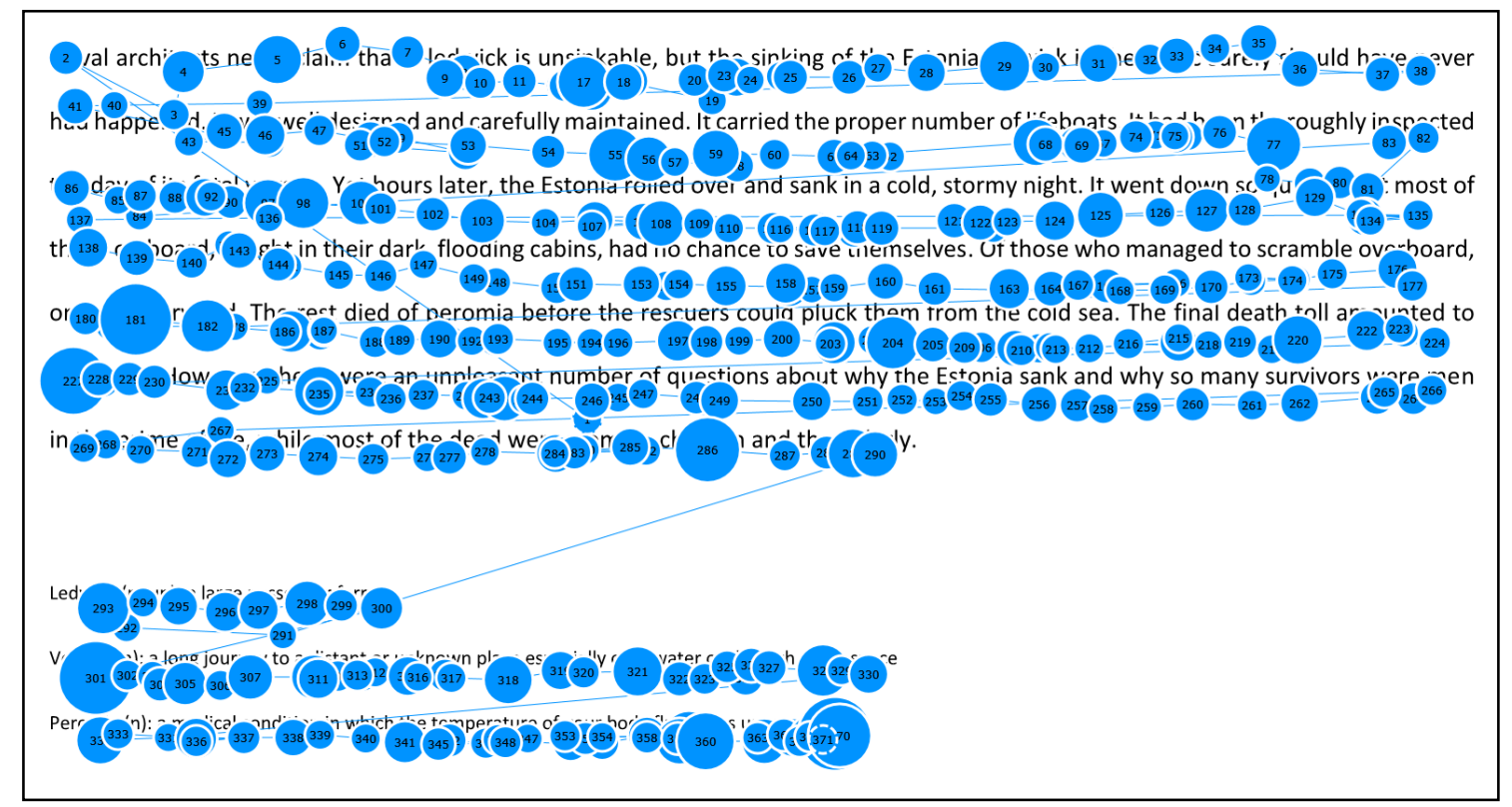

FIGURE 4. P07G1's scanpath when reading a glossed passage (Passage C)

In a way it is good to note that the research participants did not ignore the glosses entirely. However, those who demonstrated the pattern illustrated in Figure 4 did not interrupt their linear reading of the glosses in their attempt to integrate information in the glosses with that in the main body. A means to attract such readers' attention back to the main body hence might be necessary. The readers might need cues such as deictic expressions (e.g., This word can be found in line 2) or colour-coding (see Figure 5) to guide their attention from the glossary area back to the main body and encourage integration of information (Jaafar \& Thang, 2020). Another alternative is to have the glosses placed on the left or right margin of the main body, in line with the paragraph, instead of at the bottom.

Naval architects never claim that a ledwick is unsinkable, but the sinking of the Estonia ledwick in
the Baltic surely should have never had happened. It was well designed and carefully maintained. It
carried the proper number of lifeboats. It had been thoroughly inspected the day of its fatal voyage.
Yet hours later, the Estonia rolled over and sank in a cold, stormy night. It went down so quickly that
most of those on board, caught in their dark, flooding cabins, had no chance to save themselves. Of
those who managed to scramble overboard, only 139 survived. The rest died of peromia before the
rescuers could pluck them from the cold sea. The final death toll amounted to 912 souls. However,
there were an unpleasant number of questions about why the Estonia sank and why so many
survivors were men in the prime of life, while most of the dead were women, children and the
elderly.
Ledwick (noun): a large passenger ferry
Voyage ( $n$ ): a long journey to a distant or unknown place especially over water or through outer space
Peromia (n): a medical condition in which the temperature of your body fluctuates uncontrollably




\section{CONCLUSION}

This paper set out to examine how ESL readers process glossed passages in English. Through analysis of the participants' eye fixations, we learned that a glossed passage, on average, was read for a longer time and fixated more compared to a non-glossed passage. Additionally, the glossed passage was read in a similar Z-path manner as other texts written in alphabetic scripts which are read from left-to-right, and downward. This Z-path reading however was interrupted when the participants read the glossary area as forward and backward saccades were made. These saccades connected the glossary and the main body, indicative of the participants' attempts at integrating information contained in the two areas. Inferential statistics conducted on the small sample did not reveal significant relationships between processing of the glosses and comprehension outcome. Descriptive statistics however suggest that longer and shorter fixations, as well as more and less frequent fixations on the glosses might not be useful nor strategic for overall comprehension. Instead, fixations that were more moderate in terms of duration and frequency were more useful. We also learned that the participants' English vocabulary knowledge played a significant role in explaining their comprehension performance. The more vocabulary they had, the better chance they had at excelling the posttest. We also saw that vocabulary knowledge might predict the way the readers, especially the ones who performed poorly in the post-test, processed the glossary. Longer and more frequent fixations on the glosses appear to be indicative of comprehension difficulties instead of strategic processing.

Although this paper has provided insights into how ESL readers processed glossed and non-glossed passages in English, some limitations need to be outlined. Firstly, our sample size was very modest. It is crucial to mention here that the main researcher attempted to use a larger and more homogeneous sample, however, the restrictions imposed at the data collection site at the time of study, coupled with the Movement Control Order that was enforced amid data collection prevented the researcher from obtaining a more ideal sample. Additionally, given the small size of the sample, there may not have been sufficient variation in our variables to arrive at significant relationships. In such cases, descriptive statistics were carried out and thus, results obtained from the analyses are only representative of the sample, not of the population. Future research would do well in using a much larger sample size so that results obtained are more representative of the population. Having said that, the limited sample size, allowed us to describe the specific experiences of the selected participants in processing glossed passages in English.

\section{ACKNOWLEDGEMENT}

This study was part of the main researcher's final year B.A. project.

\section{REFERENCES}

Ariew, R., \& Ercetin, G. (2004). Exploring the potential of hypermedia annotations for second language reading. Computer Assisted Language Learning, 17, 237-259.

Bailin, A., \& Grafstein, A. (2001). The linguistic assumptions underlying readability formulae: A critique. Language \& Communication, 21(3), 285301. https://doi.org/10.1016/S0271-5309(01)00005-2

Cheng, Y., \& Good, R. L. (2009). L1 glosses: Effects on EFL learners' reading comprehension and vocabulary retention. Reading in a Foreign Language, 21(2), 119-142.

Chuang, Y. Y., Vollmer, M. L., Shafaei-Bajestan, E. et al. (2021). The processing of pseudoword form and meaning in production and comprehension: A computational 
modeling approach using linear discriminative learning. Behavior Research Methods, 53, 945-976. https://doi.org/10.3758/s13428-020-01356-w

Cohn, N. (2013). Navigating comics: an empirical and theoretical approach to strategies of reading comic page layouts. Frontiers in Psychology, 4, 186. doi:10.3389/fpsyg.2013.00186

de Groot, A. M. B., \& van Hell, J. G. (2005). The learning of foreign language vocabulary. In J. F. Kroll \& A. M. B. de Groot (Eds.), Handbook of bilingualism: Psycholinguistic approaches (pp. 9-29). New York: Oxford University Press.

Get your document's readability and level statistics. (2018). Retrieved from https://support.office.com/en-us/article/get-your-document-s-readability-and-levelstatistics-85b4969e-e80a-4777-8dd3-f7fc3c8b3fd2?ui=en-US\&rs=enUS\&ad=US\# toc342546557

Godfroid, A. (2019). Eye tracking in second language acquisition and bilingualism: A research synthesis and methodological guide. Routledge: New York.

Golonka, E. M., Bowles, A. R., Frank, V. M., Richardson, D. L., \& Freynik, S. (2014). Technologies for foreign language learning: A review of technology types and their effectiveness. Computer Assisted Language Learning, 27(1), 70-105. doi:10.1080/09588221.2012.700315

Grabe, W. (2009). Reading in a second language: Moving from theory to practice. Cambridge: Cambridge University Press.

Horst, J. S. (2013). Context and repetition in word learning. Frontiers in Psychology, 4, 149. https://doi.org/10.3389/fpsyg.2013.00149

Jaafar, N. M. \& Thang, S. M. (2020). Processing of a multi-representational science passage by ESL learners. GEMA Online ${ }^{\circledR}$ Journal of Language Studies, 20(4), 18-29. http://dx.doi.org/10.17576/gema-2020-2004-02

Just, M. A., \& Carpenter, P. A. (1980). A theory of reading: From eye fixations to comprehension. Psychological Review, 87(4), 329-354.

Khezrlou, S., Ellis, R., \& Sadeghi, K. (2017). Effects of computer-assisted glosses on EFL learners' vocabulary acquisition and reading comprehension in three learning conditions. System, 65, 104-116.

Koda, K. (2004). Insights into Second Language Reading: A cross-linguistic approach. Cambridge: Cambridge University Press.

Lemhöfer, K., \& Broersma, M. (2012). Introducing LexTALE: A quick and valid lexical test for advanced learners of English. Behavior Research Methods, 44(2), 325-343. doi:10.3758/s13428-011-0146-0

Mason, L., Tornatora, M. C., \& Pluchino, P. (2013). Do fourth graders integrate text and picture in processing and learning from an illustrated science text? Evidence from eyemovement patterns. Computers \& Education, 60(1), 95-109. https://doi.org/http://dx.doi.org/10.1016/j.compedu.2012.07.011

Mason, L., Tornatora, M., \& Pluchino, P. (2015). Integrative processing of verbal and graphical information during re-reading predicts learning from illustrated text: an eye-movement study. Reading and Writing, 28(6), 851-872. https://doi.org/10.1007/s11145-0159552-5

Mohd Yusof, S., Mohd Lazim, Z., Salehuddin, K., \& Mohamad Shahimin, M. (2020). Graphic novels: Understanding how fifth graders read literary text through eye movement analysis. Kritika Kultura. 33/34, 388-427. http://dx.doi.org/10.13185/KK2020.03320

Nation, I. S. P. (2001). Learning vocabulary in another language. New York: Cambridge University Press. 
Nation, I. S. P. (2006). How large a vocabulary is needed for reading and listening? Canadian Modern Language Review, 63(1), 59-82.

Rayner, K., Chace, K. H., Slattery, T. J., \& Ashby, J. (2006). Eye movements as reflections of comprehension processes in reading. Scientific Studies of Reading, 10(3), 241-255. doi:10.1207/s1532799xssr1003_3

Rayner, K. (2009). Eye movements and attention in reading, scene perception, and visual search. The Quarterly Journal of Experimental Psychology, 62(8), 1457-1506. doi:10.1080/17470210902816461

Plass, J. L., Chun, D. M., Mayer, R. E., \& Leutner, D. (2003). Cognitive load in reading a foreign language text with multimedia aids and the influence of verbal and spatial abilities. Computers in Human Behavior, 19(2), 221-243. https://doi.org/https://doi.org/10.1016/S0747-5632(02)00015-8

Plass, J. L., \& Jones, L. C. (2005). Multimedia learning in second language acquisition. In R. E. Mayer (Ed.), The Cambridge Handbook of Multimedia Learning (pp. 467-488). New York: Cambridge University Press.

Scheiter, K., \& Eitel, A. (2017). The use of eye tracking as a research and instructional tool in multimedia learning. In C. A. Was, F. J. Sansosti, \& B. J. Morris (Eds.), Eye-tracking technology applications in educational research (pp. 143-164). Hershey, PA: IGI Global.

Schmitt, N. (2008). Review article: Instructed second language vocabulary learning. Language Teaching Research, 12(3), 329-363. doi:10.1177/1362168808089921

Sulaiman, N. A., Salehuddin, K., \& Khairuddin, R. (2018). Academic word list knowledge of Malaysian ESL undergraduates. GEMA Online ${ }^{\circledR}$ Journal of Language Studies, 18(4), 1-14. http://doi.org/10.17576/gema-2018-1804-01

Sulaiman, N. A., Salehuddin, K., \& Khairuddin, K. (2020). Reading English academic texts: Evidence from ESL undergraduates' eye movement data. 3L: Language, Linguistics, Literature $^{\circledR}, 26(1), 60-78$. http://doi.org/10.17576/3L-2020-2601-05

Tham, I., Chau, M. H., \& Thang, S. M. (2019): Bilinguals' processing of lexical cues in L1 and L2: an eye-tracking study. Computer Assisted Language Learning, 33(7). doi: 10.1080/09588221.2019.1588329

Warid Mihat, Hazita Azman, \& Soh, O. K. (2018). Bringing reading research in multilingual Nusantara into a new direction through eye-tracking. Journal of Nusantara Studies (JONUS), 3(2), 107-123.

Warren, P., Boers, F., Grimshaw, G., \& Siyanova-Chanturia, A. (2018). The effect of gloss type on learners' intake of new words during reading: Evidence from eye-tracking. Studies in Second Language Acquisition, 40(4), 883-906. doi:10.1017/S0272263118000177

\section{ABOUT THE AUTHORS}

Izzammuddin Isnin is a final year B.A. student majoring in English Language Studies at the Centre for Research in Language and Linguistics, Faculty of Social Science and Humanities, Universiti Kebangsaan Malaysia (UKM). His research interests include the use of eye tracking methodology in vocabulary learning. He can also be contacted via this email: izzammuddin30@gmail.com

Nurjanah Mohd Jaafar is a lecturer at the Centre for Research in Language and Linguistics, UKM. Her research focuses on the use of multiple representations (especially text and graphics) in learning by second language speakers. She primarily uses the eye-tracking methodology in her research. 